\title{
PREDICTION OF SHEAR FAILURE OF LARGE BEAM BASED ON FRACTURE MECHANICS
}

\section{VLADIMIR CERVENKA, JAN CERVENKA, RADOMIR PUKL, TEREZA SAJDLOVA}

\author{
Cervenka Consulting \\ Prague, Czech Republic \\ e-mail: vladimir.cervenka@cervenka.cz
}

Key words: Shear failure, Reinforced Concrete, Crack Band, Cohesive Fracture, Finite element method

\begin{abstract}
A large beam tested at Toronto University for a prediction contest was simulated by the authors using a nonlinear finite element code. Their entry was chosen as the overall winner of the prediction contest and was a motivation for this case study. The crack propagation was modeled by a smeared crack approach and a fracture mechanics-based cohesive crack model. The paper discusses the model sensitivity to mesh sizes and fracture parameters. A parameter study was performed to examine the model uncertainty of numerical simulation. A probabilistic model of concrete non-homogeneity was used to reflect a more realistic strain localization in the smeared crack model.
\end{abstract}

\section{INTRODUCTION}

Blind prediction benchmarks based on experiments are often performed for validation of computational models. Recently, the "Prediction contest for strength of four meter deep reinforced concrete slab strip" organized by M.P. Collins and E.C. Bentz from University of Toronto [1] was aimed at large structures, where size becomes an important factor. The strength prediction submitted by the authors was chosen as the best among 66 participants. The Toronto contest includes two tests, one without shear reinforcement and other with stirrups. Only the first test exhibiting a typical shear failure due to a diagonal crack is treated in this paper.

The authors simulated the specimen behavior, namely the crack propagation, by the finite element method with a constitutive model based on the smeared crack with crack band regularization. At the phase of the prediction, when the experimental response was not known a sensitivity to model parameters was experienced. This poses a problem for the right choice of model parameters relevant for fracture analysis. The laboratory test provided the concrete compressive strength as the only parameter describing the concrete properties. The other parameters, such as tensile strength and fracture energy were not tested. In this situation, which is typical in practice, one has to rely on derivation of these parameters from generally known relations from codes and other research sources. Further, an effect of the finite element size should be reduced. At the phase of prediction authors based these choices on experience gained from other validations [4], [5]. After a publication of the contest results [1] an investigation of parameter sensitivity was conducted, with the aim to describe the model uncertainty of the simulation method. 


\section{NUMERICAL MODEL}

The specimen representing a $0.25 \mathrm{~m}$ wide strip of a $4 \mathrm{~m}$ deep slab, as shown in Error! Reference source not found., has the support span of $19 \mathrm{~m}$, is loaded by the force positioned nonsymmetrically and provided by shear reinforcement in the left shear span only. The bottom reinforcement is by 9 bars of $30 \mathrm{~mm}$ diameter in 3 layers. Concrete strength is 40 $\mathrm{MPa}$. It is designed so that it would fail first in the right shear span denoted as the east test, with a/d ratio 3.12 while that of the left span denoted as the west test with a/d ratio 1.82 is expected to have an increased strength.

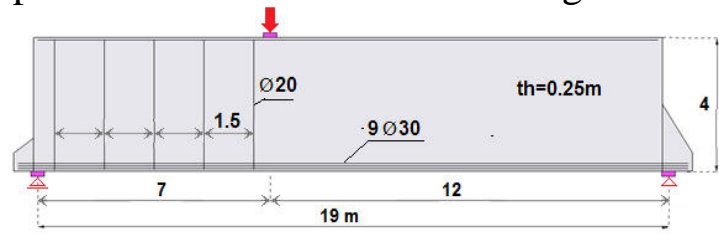

Figure 1: Test specimen geometry.

The finite element model is made for a plane stress simplification, with low order quadrilateral isoparametric elements with $2 \times 2$ integration scheme, with the square elements shape and size of $100 \mathrm{~mm}$, i.e. 20 elements through the height. The loading is applied by the imposed displacement on the top loading plate and the force is obtained as a reaction. About 50 load steps to the peak were used. Iterations were controlled by the error 0.001 (ratio of norms of vectors due to residual forces and loading forces).

The smeared crack analyses performed in this investigation were made with the program ATENA [7] using the combined fractureplastic model for concrete of Červenka \& Pappanikolaou [6].

The constitutive model formulation assumes small strains, and is based on the strain decomposition into elastic $\left(\varepsilon_{i j}^{e}\right)$, plastic $\left(\varepsilon_{i j}^{p}\right)$ and fracture $\left(\varepsilon_{i j}^{f}\right)$ components. The stress development is described by the rate equations reflecting the progressive damage (concrete cracking) and plastic yielding (concrete crushing):

$$
\dot{\sigma}_{\mathrm{ij}}=\mathrm{D}_{\mathrm{ijkl}} \cdot\left(\dot{\varepsilon}_{\mathrm{kl}}-\dot{\varepsilon}_{\mathrm{kl}}^{\mathrm{p}}-\dot{\varepsilon}_{\mathrm{kl}}^{\mathrm{f}}\right)
$$

Flow rules govern the evolution of plastic and fracturing strains:

Plastic model: $\quad \dot{\varepsilon}_{\mathrm{ij}}^{\mathrm{p}}=\dot{\lambda}^{\mathrm{p}} \cdot \mathrm{m}_{\mathrm{ij}}^{\mathrm{p}}, \mathrm{m}_{\mathrm{ij}}^{\mathrm{p}}=\frac{\partial \mathrm{g}^{\mathrm{p}}}{\partial \sigma_{\mathrm{ij}}}$

Fracture model: $\quad \dot{\varepsilon}_{\mathrm{ij}}^{\mathrm{f}}=\dot{\lambda}^{\mathrm{f}} \cdot \mathrm{m}_{\mathrm{ij}}^{\mathrm{f}}, \mathrm{m}_{\mathrm{ij}}^{\mathrm{f}}=\frac{\partial \mathrm{g}^{\mathrm{f}}}{\partial \sigma_{\mathrm{ij}}}$

Where $\dot{\lambda}^{p}$ is the plastic multiplier rate and $g^{p}$ is the plastic potential function, $\dot{\lambda}^{f}$ is the inelastic fracturing multiplier and $g^{f}$ is the potential defining the direction of inelastic fracturing strains. The multipliers are evaluated from consistency conditions.

The model of Menetrey-Willam [6] is used for plasticity of concrete in multiaxial stress state in compression.

In tension, Rankine criterion for tensile fracture with exponential softening of Hordijk [8] (see Figure 1) is used, where $w_{t}$ stands for the crack width.

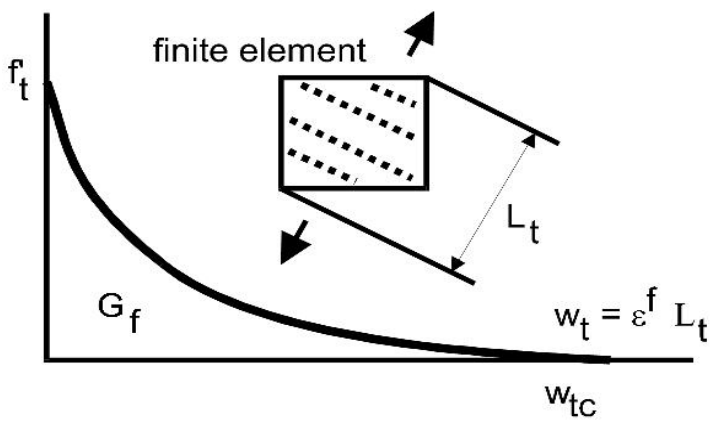

Figure 2: Crack opening law according to Hordijk [8].

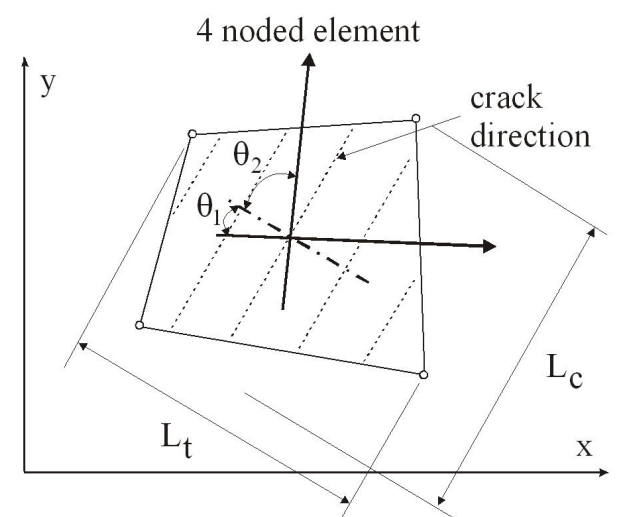

Figure 3: Crack band formulation. 
The stress softening in tension is determined using the crack band approach of Bažant \& Oh [2] and analogically in compression according to Cervenka et.al [11]. The crack band $L_{t}$ as well as the crush band size $L_{c}$ are adjusted with regard to the crack orientation approach proposed by Cervenka et al. [9]. This method is illustrated in Figure 2, Figure 3 and described by Eq.(4)

$\mathrm{L}_{\mathrm{t}}^{\prime}=\alpha \gamma \mathrm{L}_{\mathrm{t}}$ and $\mathrm{L}_{\mathrm{c}}^{\prime}=\gamma \mathrm{L}_{\mathrm{c}}$

$\gamma=1+\left(\gamma_{\max }-1\right) \frac{\theta}{45}, \theta \in\langle 0 ; 45\rangle, \gamma_{\max }=1.5$

The crack angle $\theta$ is taken as the average angle between crack direction and element sides.

The above formulation serves to control the strain localization accounting for the mesh size and the crack orientation. Parameter $\alpha$ is introduced to cover the localization effect due to the element type as reported recently in the work of Slobbe et al. [3]. In this study $\alpha=1$ is used for low order elements with $2 \times 2$ integration scheme and $\alpha=0.6$ for quadratic elements with $3 \times 3$ integration scheme.

Some additional features of cracked concrete included in the model, namely the reduction of compressive strength and shear stiffness degradation, often referred as a shear retention effect, should be mentioned due to their importance for the given problem.

The damage of concrete by cracks is reflected according to Bentz et al.[10] in the reduction factor $r_{c}$ of the compressive strength $f_{c}$ as follows:

$\sigma_{c}=r_{c} f_{c}$

$r_{c}=\frac{1}{0.8+170 \varepsilon_{1}}, r_{c}^{\lim } \leq r_{c} \leq 1.0$

where $\varepsilon_{1}$ is the tensile strain normal to the crack. The largest maximal fracturing strain is used for $\varepsilon_{1}$ and the compressive strength reduction is limited by $r_{\mathrm{c}}{ }^{\lim }$. In this work $r_{\mathrm{c}}{ }^{\mathrm{lim}}=$ 0.8
The shear strength of the cracked surface is also considered according to the modified compression field theory - MCFT [10]:

$$
\sigma_{i j} \leq \frac{0.18 \sqrt{f_{c}^{\prime}}}{0.31+\frac{24 w}{a_{g}+16}} ; \quad i \neq j
$$

It takes into account the crack width $w$ and aggregate size $a_{g}$. Since MCFT does not offer a shear stiffness, the authors proposed to relate the shear stiffness $K_{t}^{c r}$, oriented tangentially to the crack face, to the normal stiffness $K_{n}^{c r}$ already defined by a crack opening law:

$$
K_{t}^{c r}=s_{F} K_{n}^{c r}
$$

The normal stiffness comes directly from the tensile softening law in Figure 2 as:

$$
K_{n}^{c r}=f_{t}\left(w_{t}\right) / w_{t}
$$

This makes the shear stiffness dependent on the crack opening displacement and independent of the mesh size. The scaling factor $s_{F}=50$ was used in the prediction stage.

The material parameters used for the prediction are listed in Table 1.

Table 1: Concrete material parameters

\begin{tabular}{|l|c|}
\hline Parameter & East test \\
\hline Elastic modulus initial $\boldsymbol{E}[\mathrm{MPa}]$ & 34129 \\
\hline Poisson ratio & 0.2 \\
\hline Compressive strength $\boldsymbol{f}_{\boldsymbol{c}}[\mathrm{MPa}]$ & 40.0 \\
\hline Tensile strength $\boldsymbol{f}_{c t}[\mathrm{MPa}]$ & 3.0 \\
\hline Fracture energy $\boldsymbol{G}_{\boldsymbol{f}}[\mathrm{N} / \mathrm{m}](\mathrm{MC} 90)$ & 78 \\
\hline Plastic disp. in compression $\boldsymbol{w}_{\boldsymbol{d}}[\mathrm{mm}]$ & 5 \\
\hline Fixed cracks & 1.0 \\
\hline Strength reduction $r_{\mathrm{c}}^{\lim }$ & 0.8 \\
\hline Shear factor $\boldsymbol{S}_{F}$ & 50 \\
\hline
\end{tabular}

\section{COMPARISON OF PREDITION WITH} TEST

A comparison of the predicted loaddisplacement diagram with experimental one is shown in

Figure 4.

The shear strength predicted by the authors was $745 \mathrm{kN}$, while the one from experiment was $685 \mathrm{kN}$. The error of the simulation was 
+9\%. The predictions of 66 participants were evenly distributed in the interval from lowest entry of $250 \mathrm{kN}$ to highest one of $3773 \mathrm{kN}$. This demonstrated that the shear strength is still a challenging task for the profession. For details see the paper by Collins et al.[1].

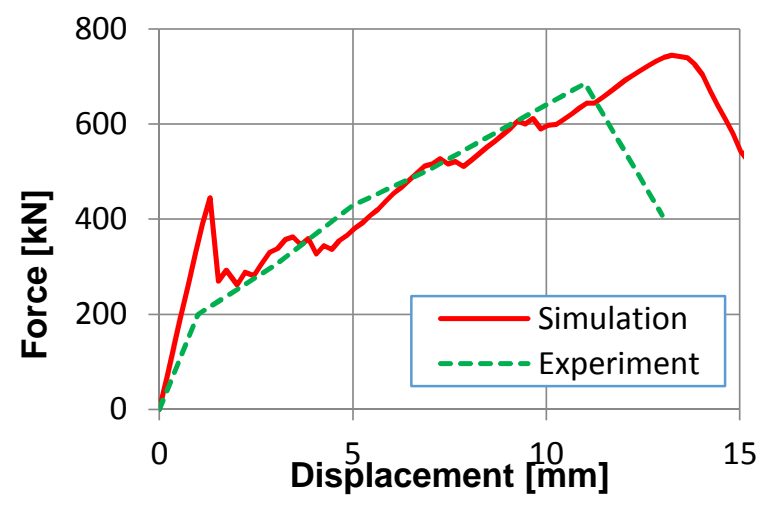

Figure 4: Comparison of load-displacement diagrams..

The failure mode was due to a diagonal crack opening as illustrated in Simulation: $P \max =745 \mathrm{kN}$

Figure 5.

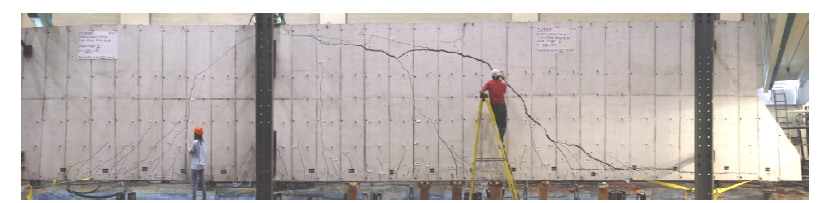

Test: $P_{\max }=685 \mathrm{kN}$

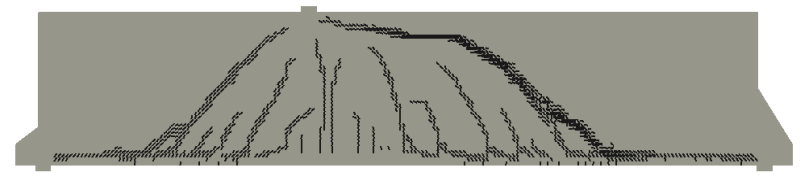

Simulation: $P_{\max }=745 \mathrm{kN}$

Figure 5: Observed and predicted crack patterns and maximal loads for $4 \mathrm{~m}$ deep slab strip.

It could be concluded from the detail analysis of results, that the formation of one diagonal crack led to the failure. The analysis was able to realistically simulate the crack location and spacing which resulted in an excellent stiffness estimation.

A discrepancy between prediction and experiment was observed at the stage of crack initiation. It is believed that this is due to inability of the model to capture the nonhomogenity of concrete and will be discussed later in the chapter on the probabilistic model.

In order to provide a direct comparison with the large beam $(h=4000 \mathrm{~mm})$ a standard size beam $(h=300 \mathrm{~mm})$ was also tested in the Toronto contest. (Cross section dimensions $h=300 \mathrm{~mm}, b=175 \mathrm{~mm}$, support span $1650 \mathrm{~mm}$, longitudinal reinforcement of $A_{s}=296 \mathrm{~mm}^{2}$, concrete strength $f_{c}=45 \mathrm{MPa}$.). A point load was applied in the center. In experiment a shear failure occurred when the applied load reached $94.8 \mathrm{kN}$. In the simulation, the failure load was found at $92.4 \mathrm{kN}$. The failure crack patterns are compared in Figure 6.

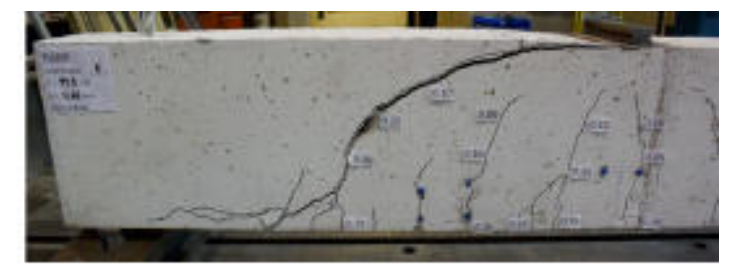

Test: $P_{\max }=95.8 \mathrm{kN}$

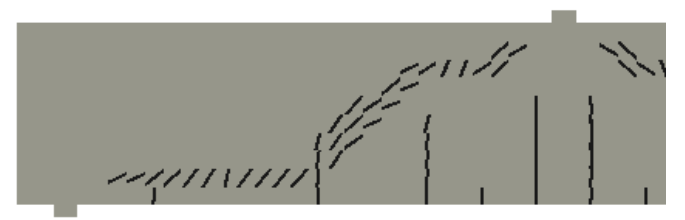

Simulation: $P_{\max }=92.4 \mathrm{kN}$

Figure 6: Observed and predicted crack patterns and maximal loads for $0.3 \mathrm{~m}$ deep specimen.

The crack widths before failure in the simulation were 0.25 and $3 \mathrm{~mm}$, for small and large beam respectively, which corresponds well to the experiment: 0.2 and $4 \mathrm{~mm}$, for the small and large beams, respectively.

It can be concluded that the numerical model simulated well the strength as well as the failure mode for beams of both sizes.

\section{PARAMETER STUDY}

After the test results were made public, the authors performed a sensitivity study on the selected model parameters. First, the mesh size effect was investigated for the element sizes $50,100,200$ and $400 \mathrm{~mm}$. The loaddisplacement diagrams are shown for low order square elements with $2 \times 2$ integration scheme in Figure 7 and for high order quadratic elements with $3 \times 3$ integration scheme in Figure 8. 
The shear factor from equation (10) was found to be an essential parameter for the study. For low shear factor values, a failure by splitting cracks along the longitudinal reinforcement was observed for some mesh sizes. Therefore $S_{F}=200$ was used for the study.

Both element types indicate systematic increase of stiffness with the mesh refinement. The response curves are almost parallel but shifted to higher resistance. This trend can be attributed to a concrete tension stiffening, i.e. contribution of a cracked concrete to the reinforcement stiffness. Apparently, in large meshes the concrete contribution is less due to a large volume of cracked concrete.

The crack patterns after failure shown in Figure 9 and Figure 10 reproduce well the experimental behavior and are consistent for both element types and all mesh sizes. Visible cracks greater than $0.2 \mathrm{~mm}$ are denoted by lines showing crack orientation in elements.

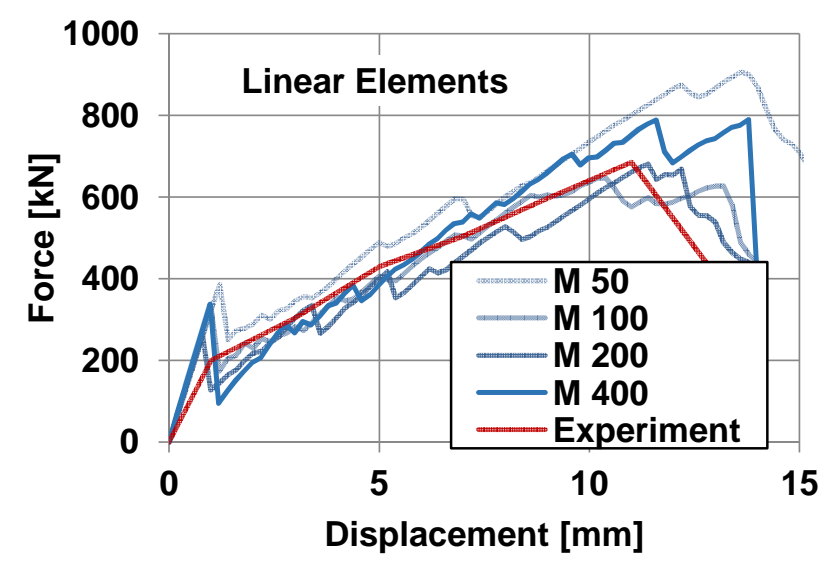

Figure 7: Mesh size effect for low order elements.

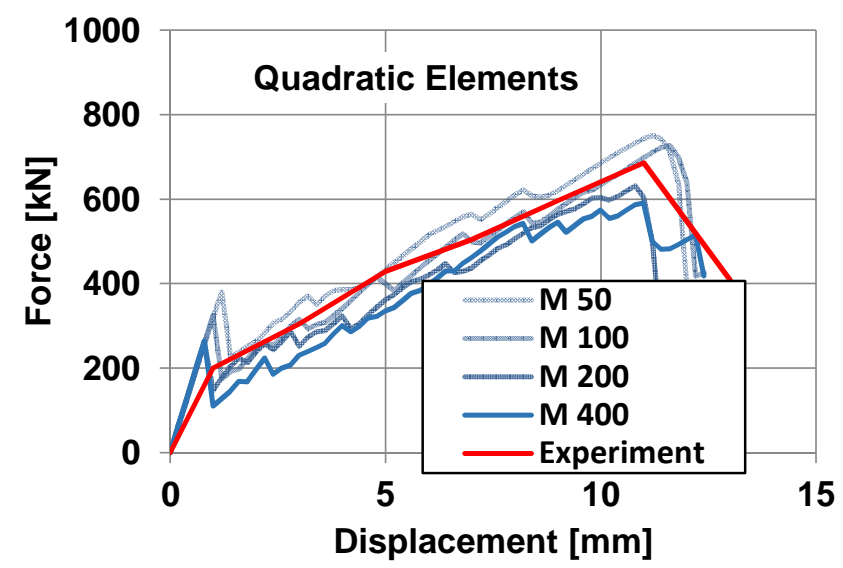

Figure 8: Mesh size effect for quadratic elements.

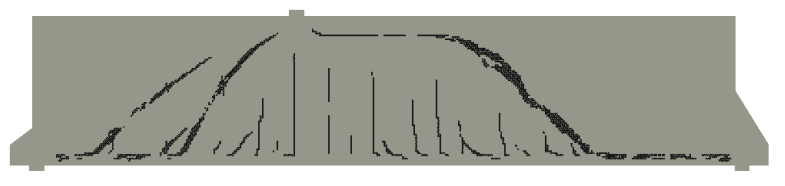

M50

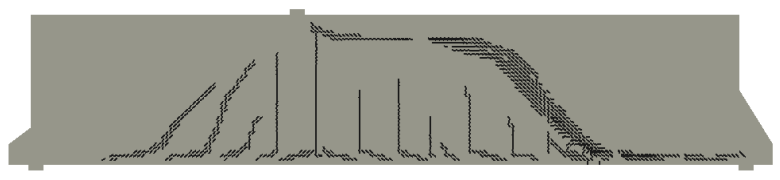

M100

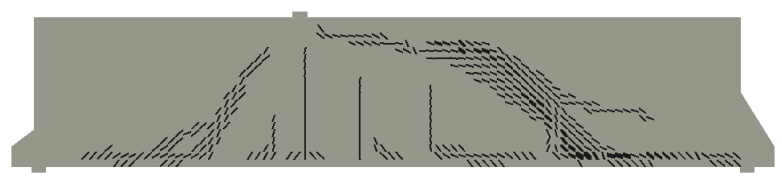

M200

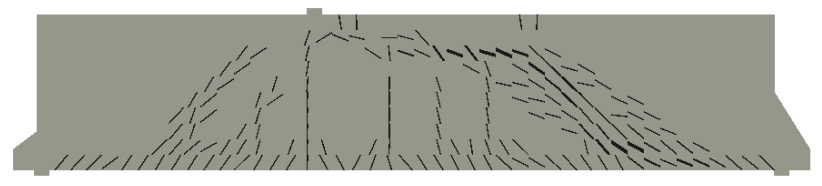

M400

Figure 9: Crack patterns for low order meshes.

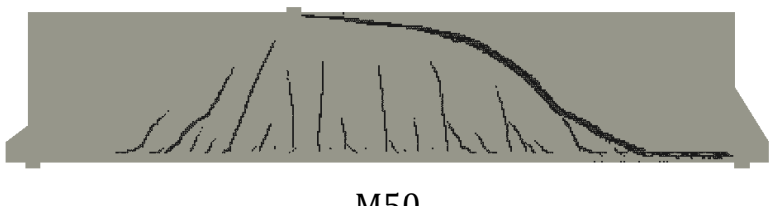

M50

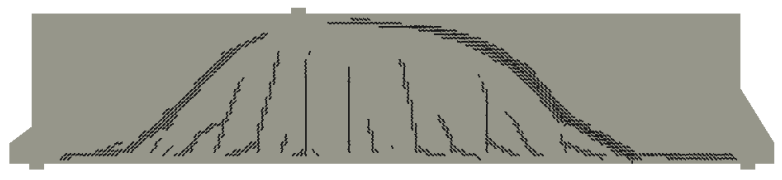

M100

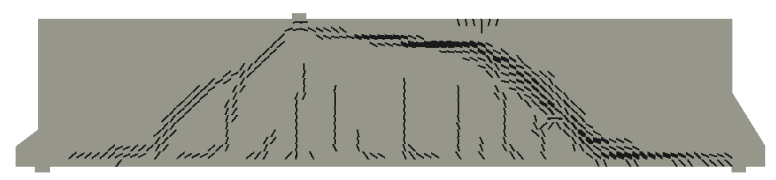

M200

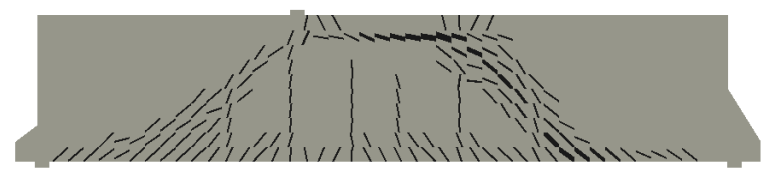

M400

Figure 10: Crack patterns for quadratic meshes. 


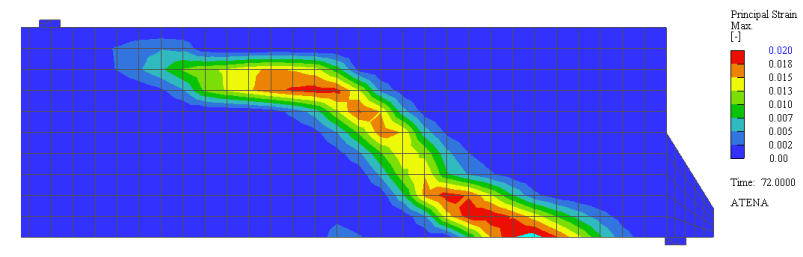

Linear M400

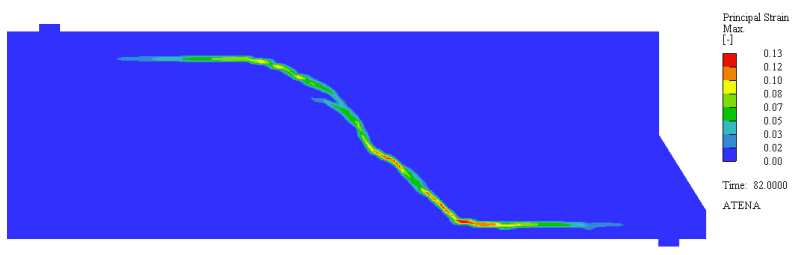

Linear M50

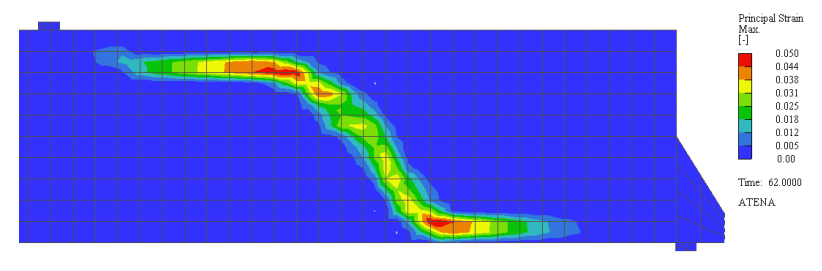

Quadratic M400

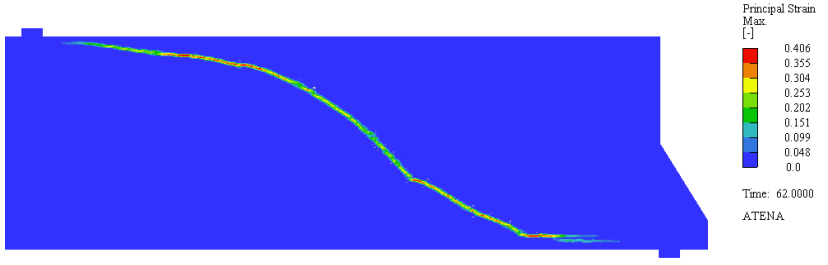

Quadratic M50

Figure 11: Strain localization.

The mesh size effect on the shear strength is stronger in linear elements. The strength range for in linear elements is $260 \mathrm{kN}$ (from 646 to $906 \mathrm{kN}$ ), for quadratic elements it is $181 \mathrm{kN}$ (from 603 to $784 \mathrm{kN}$ ). This is probably caused by different crack paths, which are the result of a strain localization in different meshes and element types. This is illustrated in Figure 11, where iso-areas of strains indicating the crack paths in early post-failure stages are compared for two meshes M400 and M50 and two element types. Such a difference can be observed, for example, between the linear and quadratic elements in mesh M400 near the bottom edge and in the mesh M50 near the top and bottom edges.

\section{PROBABILISTIC MODEL}

The effect of two fracture parameters, tensile strength $f_{t}$ and fracture energy $G_{f}$, was investigated using a probabilistic model. This study was motivated by the observed discrepancy between the simulated and test response diagrams in the stage of the crack initiation. This is illustrated in Figure 12, where a "jump" in the simulated response diagram at point $\mathrm{A}$ is caused by a sudden propagation of a vertical crack at point $\mathrm{B}$. This can be explained by the instability of the softening solution in the nearly uniform field of smeared cracks with a sudden strain localization. Such response was not observed in the experiment. It is believed that in a real material the localization is triggered by imperfections in early stages of cracking and large homogenous crack fields do not appear.

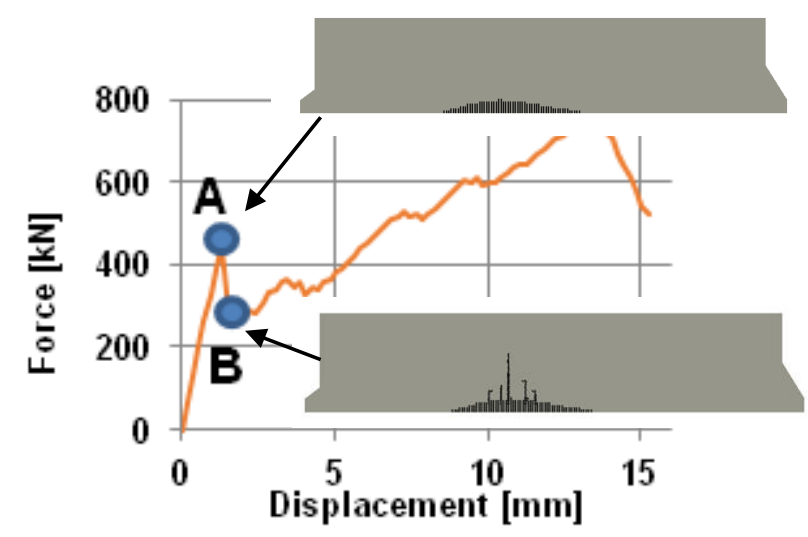

Figure 12: Strain localization at the crack initiation.

In attempt to explain this behavior a probabilistic model was developed using the software SARA, which is based on the work of research group in Brno Technical University reported by Vorechovsky [12].

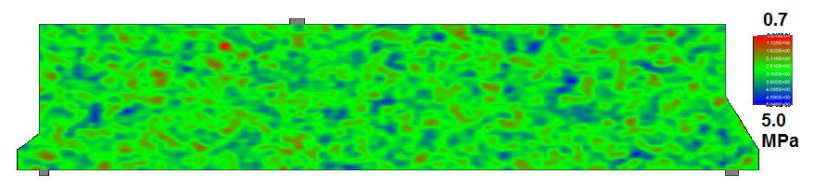

tensile strength $f_{t}$

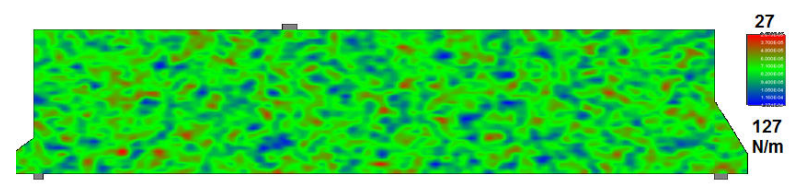

fracture energy $G_{f}$

Figure 13: Example of random fields.

In the probabilistic model, two material parameters deciding about the fracture response, namely tensile strength and fracture energy, are modeled as random fields over the 
two dimensional domain of the strip as shown in Figure 13. The fields are generated under the assumption of normal distribution with average values of parameters given in Table 1, coefficient of variation 0.2 and two correlation lengths, 0.2 and $0.1 \mathrm{~m}$ for horizontal and vertical directions respectively.

A set of 32 simulations was generated using the LHS sampling resulting in loaddisplacement diagrams shown in Figure 14.

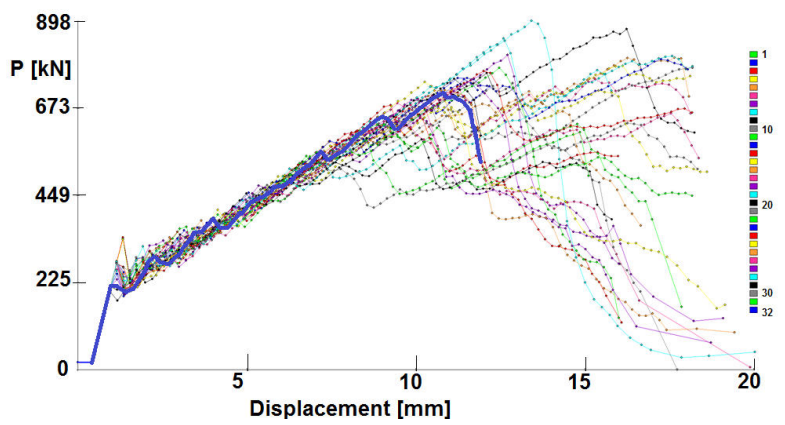

Figure 14: Response diagrams generated by random fields.

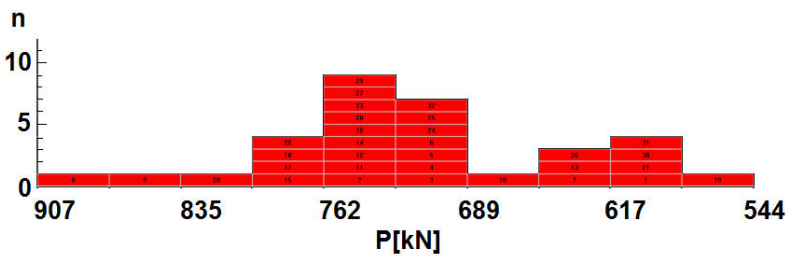

Figure 15: Strength histogram of random test simulations.

It can be observed that some simulations do not show the stability jump at the crack initiation and thus simulate well the experimental response.

The average strength $690 \mathrm{kN}$ from random simulations corresponds well with the one from experiment $685 \mathrm{kN}$. The range of random strength values is $363 \mathrm{kN}$ (from 544 to 907 $\mathrm{kN})$. The scatter is obviously directly dependent on the assumed variability of random fields. More data describing the nonhomogenity distribution in real structures are required for further improvement of this exercise.

In the view of the above scatter of the shear strength it would be of interest to know the scatter if a group of nominally identical specimens would be tested.

\section{CONCLUDING REMARKS}

The finite element analysis based on the smeared crack approach and fracture mechanics provided a realistic prediction of slab strip behavior tested experimentally in Toronto shear contest. It was shown that the model has good capability to describe a size effect in shear strength. However, significant uncertainties are involved and should be considered in result interpretation.

The Toronto contest criteria for a demanding prediction of strength were set as $+/-10 \%$. The parameter study indicated much larger scatter due to model as well as material uncertainties.

The model uncertainties were investigated for two element types, linear and quadratic, and for four mesh sizes. The experimental response described by a load-displacement curve was located approximately in the average of all simulations. The uncertainty of strength due to mesh size effect described by the range of strengths was $38 \%$ (i.e. $+/-19 \%$ about average) for linear elements and $26 \%$ (i.e. +/- 13\%) for quadratic elements (with reference to the experimental strength).

Considering strength prediction the mesh sizes of 100 and $200 \mathrm{~mm}$ provided the best results close to mean (and also to experiment), while the extreme sizes 50 and $400 \mathrm{~mm}$ gave worse results. Thus, element sizes close to sizes of usual material test specimen $(150 \mathrm{~mm})$ seems to be optimal. Extremely large elements (400 $\mathrm{mm}$ ) provided safe and conservative strength. Extremely fine meshes $(50 \mathrm{~mm})$ gave excellent crack patterns.

The probabilistic model revealed, that a "jump" during the initial crack propagation can be explained by the homogenous material assumed in the model. An introduction of randomly distributed material properties helped to reduce this discrepancy.

The probabilistic study indicated also an effect of material random variability on strength, which was in the range of $53 \%$ (or $+/-26 \%$ ) of the shear strength. No attempt was made to evaluate a safety factor based on the reliability analysis, which will be part of a subsequent research. 
The present study offered interesting answers to many questions related to the Toronto contest, while it also opened many questions. It is a motivation for a future research to derive partial safety factors for large structures for material and model uncertainties based on probabilistic safety formats.

Furthermore, it is a challenge for future research to investigate alternative ways of modeling crack discontinuities and reducing model uncertainties.

Finally, a comment on prediction strategy. In the prediction stage, often with limited time available, questions about appropriate material parameters and suitable numerical model are at stake. For this purpose a default set of parameters relevant for a given constitutive model and concrete type must be defined and validated. A numerical model, namely the element type and mesh size should be based on experience gained from cases similar to the analyzed one. In the real world, engineers face this situation every day.

\section{ACKNOWLEDGEMENT}

The authors would like to acknowledge the financial support of Czech Science Foundation project 16-04132S, Epistemic uncertainty of crack models in reinforced concrete structures.

\section{REFERENCES}

[1] Collins, M.P., et al.: Challenge of Predicting the Shear Strength of Very Thick Slabs. Concrete International, V.37,No.11, Nov. 2015, pp 29-37.

[2] Bazant, Z.P., Oh, B.H., 1983. Crack band theory for fracture of concrete. Materials and Structures, RILEM 16 (3), 155-177.

[3] Slobbe A.T., Hendriks M.A.N., Rots J.G. Systematic assessment of directional mesh bias with periodic boundary conditions: Applied to the crack band model. Engineering Fracture Mechanics, V. 109, September 2013, Pages 186-208.

[4] Galmarini A., Lochner D.,Marti P. Predicting the response of reinforced concrete slab strips subjected to axial tension and transverse load: a competition.
Structural Concrete Volume 16, Issue 2, pages 172-183, June 2015

[5] Cervenka, V., Cervenka, J., Jendele, L., Smulauer, V., ATENA simulation of crack propagation in CONCRACK benchmark, European Journal of Environmental and Civil Engineering, Taylor Francis, Vol.18, No.7, 2014, DOI: 10.1080/19648189.2014.881757. Pp. 828844

[6] Cervenka J, Papanikolaou V.K. Three dimensional combined fracture-plastic material model for concrete. Int. J. Plast. 2008;24:2192-220. doi:10.1016/j.ijplas. 2008.01.004.

[7] Cervenka, J., Jendele, L., Cervenka, V. 2015. ATENA Program documentation.

Cervenka Consulting, www.cervenka.cz.

[8] Hordijk, D.A. Local approach to fatigue of concrete. PhD Thesis, Delft University of Technology, 1991.The Netherlands.

[9] Cervenka, V., and Margoldova, J., Tension Stiffening Effect in Smeared Crack Model, Engineering Mechanics, Stain Sture (Eds), Proc. 10th Conf., Boulder, Colorado, 1995.pp. 655-658.

[10]Bentz, E.C., Vecchio, F.J., Collins, M.P. 2006. Simplified Modified Compression Field Theory for Calculating Shear Strength of Reinforced Concrete Elements. ACI Material Journal, Jul/Aug 2006.

[11]CERVENKA， J., CERVENKA, V., LASERNA S., On finite element modelling of compressive failure in brittle materials, Computational Modeling of Concrete Structures. Bicanic et al.(Eds),Euro-C 2014, St. Anton, Austria, Tazlor \& Francis Group, London, ISBN 978-1-138-00145-9, pp.273-281.

[12]Vorechovsky M., Novak D. Simulation of randomfields for stochastic finite element analysis. ICOSSAR 2005, G. Augusti, G.I. Schuëller, M. Ciampoli (eds) 2005 Millpress, Rotterdam, ISBN 905966040 4

[13]SARA. Software for Probabilistic Analysis of Reinforced Concrete Structures. 2015. www.cervenka.cz 